UMr.

DOWNSTREAM LABELING AND UPSTREAM PRICE COMPETITION

BONROY Olivier ; LEMARIE Stéphane

May 2010

JEL CODES : L15 ; L50

KEYWORDS : LABEL ; IMPERFECT CONSUMER INFORMATION ; VERTICAL PRODUCT DIFFERENTIATION ; VERTICAL RELATIONS ; REGULATION

Working Paper GAEL ; 2010-01

Institut National de la Recherche Agronomique - Université Pierre Mendès France Unité Mixte de Recherche 1215

Domaine Universitaire - BP 47 - 38040 GRENOBLE Cedex 9

Tél. : 33 (0) 476825439 - Fax : 33 (0) 476825455

E-mail : vertier@grenoble.inra.fr - http://www.grenoble.inra.fr 


\title{
Downstream labeling and upstream price competition
}

\author{
Olivier BONROY*†‡, Stéphane LEMARIÉ ${ }^{\dagger \ddagger}$
}

May 2010

\begin{abstract}
This paper analyses the economic consequences of labeling in a setting with two vertically related markets. Labeling on the downstream market affects upstream price competition through two effects: a differentiation effect and a ranking effect. The magnitude of theses two effects determines who in the supply chain will receive the benefits and who will bear the burden of labeling. For instance, whenever the ranking effect dominates the differentiation effect, the low-quality upstream firm loses from labeling while all downstream actors are individually better off. By decreasing the low quality input price, the label acts then as a subsidy which assures an increase of the downstream market welfare. This analysis furthers our understanding of the economic consequences of the public labeling in cases like restaurants or GMOs.
\end{abstract}

Keywords: Label, Imperfect consumer information, Vertical product differentiation, Vertical structure.

JEL classification: L15, L5.

${ }^{*}$ Corresponding author. INRA, Université Grenoble 2, UMR 1215 GAEL, Domaine universitaire, BP 47, 38040 Grenoble Cedex 9, France. E-mail: olivier.bonroy@grenoble.inra.fr.

†INRA, UMR 1215 GAEL, F-38000 Grenoble, France

$\ddagger$ Université Grenoble 2, UMR 1215 GAEL, F-38000 Grenoble, France 


\section{Introduction}

In the last decade governments greatly increase the implementation of production attribute labels. For example, in France publics labels enable restaurants to indicate that their food is produced with regional and fresh ingredients. In the US, some eggs, poultry and beef products carry labels regulated by the USDA such as "organic" and "no hormones". In Austria and in Germany, a public label provides consumers with the certainty that foodstuffs with this label contain no genetically modified ingredients. These examples share two important features. First, products come from a rather long supply chain with no information problem in the upstream part and an information asymmetry in the downstream part. Second, the implementation of a label to solve the information problem in the downstream part may reverse the ranking of products in the upstream part.

To illustrate this general problem, consider the restaurants in tourist areas. Two upstream industries supply either fresh or frozen ingredients to restaurants and the output is then supplied to the consumers. Restaurants located in tourist areas cannot build reputation: consumers generally visit restaurant only once, without having any ex-ante information on the quality of the food. So, restaurants that supply meals cooked with fresh, regional ingredients can hardly be differentiated from restaurants that used frozen, non-regional ingredients (generally precooked food). Local foods prepared with fresh, regional ingredients are unanimously preferred by consumers. However, without a signal, restaurants have little interest in providing the local foods and would prefer to use the frozen ingredients, which are more cost saving because easier and quicker to prepare. The French public label Maitre Restaurateur, implemented in 2007, guarantee that foods are cooked with fresh and regional ingredients. This label may reverse the preferences of restaurants. By signaling with such a label, consumer willingness to pay increases for the foods produced in these restaurant. Despite their technical and cost advantages at the restaurant level, frozen ingredients are now considered low-quality inputs because consumers have a lower willingness to pay for the foods produced with these ingredients.

Consider a more controversial case, products produced from genetically modified organisms (GMO). Monsanto, the leading US company in the development of GMOs, sells its technology in seeds to farmers, not to the final consumers. Seeds are differentiated in the upstream market. Relative to the conventional seeds, GMOs seeds provide farmers cost savings. ${ }^{1}$ Experimental studies provide evidence that the consumer willingness to pay for products produced with GMOs in the downstream market significantly decreases once the products are labeled (Noussair et al., 2004, Lusk et al., 2005). We can infer that, with labeling, GMO seeds are low-quality inputs,

\footnotetext{
${ }^{1}$ GMOs seeds have a technical advantage for the farmer because they enable better pest control.
} 
despite technical cost advantages for the farmers.

This stylized fact about the reversal of quality ranking in downstream markets has not generally been considered by the literature. Unlike the present paper, the existing literature on quality certification instruments is largely based upon vertical product differentiation models where only the final market is considered. For instance, in a typical vertical differentiation oligopoly, as in Gabszewicz and Thisse (1979) or Shaked and Sutton (1982), more information about product quality leads to an increase in both product differentiation and firms' profits. Indeed, with imperfect information about the quality, products are considered homogeneous and Bertrand competition drives profits to zero. ${ }^{2}$ Labeling enables firms to differentiate their products and therefore reduces competition. As long as it is not too costly, all firms gain from certification even the low-quality firm. Garella and Petrakis (2008) extend this analysis by assuming a Dixit-Spence-Bowley model of demand. These authors show that a minimum quality standard increases the firms' returns from quality improving investments. As a consequence firms are better off. In contrast, two recent papers show that labeling may intensify competition too. Roe and Sheldon (2007) show that public labeling may drive prices down and decrease the profit of the low-quality firm when the market is not perfectly contestable. ${ }^{3}$ Bonroy and Constantatos (2008) consider that products are differentiated under imperfect information because consumers have different beliefs concerning the trustworthiness of each firm. These beliefs may converge after labeling, leading to more intense competition and lower profits for the suppliers.

The few papers that consider the effect of labeling with a longer supply chain can be found in literature about GMOs. However, unlike the present paper, strategic interaction between upstream suppliers is absent in their analysis. Lapan and Moschini (2007) assume competitive farmers and a competitive processing industry. They find that the labeling standard preferred by farmers would be stricter than what is optimal for consumers and for societal welfare. Fulton and Giannakas (2004) consider a supplier of GMO seed (the life science company) with some market power and competitive farmers. ${ }^{4}$ They show that the preferences for GMO labeling for farmers, consumers and the life science company are different. ${ }^{5}$

\footnotetext{
${ }^{2}$ This outcome is negated if the high-quality firms can credibly inform consumers about quality by using ex ante mechanisms such as advertising, price signaling or reputation.

${ }^{3}$ See also Marette (2007) for the analysis of a minimum quality standard when the market is non perfectly contestable.

${ }^{4}$ Fulton and Giannakas (2004) assume that high-quality seed (conventional seed) is supplied at constant and exogenous price, but they recognize that strategic interactions between both seed industries may exist in real world: "Industry evidence suggests, however, that the price of the traditional seed and pesticide packages may change after the introduction of the GM crops." (p.47).

${ }^{5}$ Labeling has no effect on seeds prices in their model. The traditional seed price is exogenous, and the GM seed equilibrium price is the same under the no-labeling and the labeling regimes because of the particular specifications of their model.
} 
The present paper analyses the economic consequences of labeling in a context of two vertically related markets. We consider a supply chain with an upstream duopoly market and a competitive downstream market characterized by heterogeneous producers and consumers. The quality of the input chosen by the downstream producer determines the quality of its output. Under imperfect information, the quality of outputs is unknown to the final consumers; therefore products can only be differentiated in the upstream market. This differentiation generates profits for both upstream firms. When a label is available, the high-quality producers adopt it, so that products are differentiated in both the upstream and the downstream markets.

Our central result is that, by revealing the quality on the downstream market, the label has two effects on the upstream price competition. First, instead of being differentiated only at the producer level, products also become differentiated at the final consumer level. The differentiation effect of labeling tends to relax price competition, as the literature on differentiated products has clearly established. Second, labeling reverses the ranking of the inputs in terms of quality and prices since the cost-saving input is used to produce the low-quality output. This effect has not been mentioned in the existing economic literature and is obtained here because of the setting with two vertically related markets. We show that the magnitude of theses two effects determines who in the supply chain will receive the benefits and who will bear the burden of labeling. For instance, whenever the ranking effect dominates the differentiation effect, the low-quality firm loses from labeling while all consumers are individually better off. This result contrasts with standard results on vertical differentiation in the literature. Furthermore, without a sufficiently large ranking effect the label fails to improve the welfare on the downstream market, i.e. the one where the label is implemented.

The paper is organized as follows: Sections 2 and 3 present the model and the equilibrium both with and without labeling. The impact of labeling is analyzed in Section 4. Different extensions are then presented in Section 5, followed by the conclusion.

\section{The model}

We consider a supply chain with two vertically related markets. In the upstream market, there are two firms $(i \in\{1,2\})$, each supplying a particular type of input to a continuum of competitive intermediary producers. For clarity, in this paper the term "firms" refers to upstream suppliers, while the term "producers" refers to intermediary producers who supply the downstream market. The final production is sold on the downstream market to a continuum of consumers. Each producer buys either zero or one unit of input and each consumer buys either zero or one unit of 
final product. We assume that one unit of input is required to produce one unit of output, and that the quality of the final product is determined by the type of input used. The high quality product is defined as the product unanimously preferred by consumers. This one is also the less cost saving for producers. This definition, central in this model, is quite realistic and can be illustrated by the GMO or the restaurant cases. In the GMO case, several studies show that consumers consider GM-free food as being of better quality (Lusk et al., 2005), but other studies show that GM-free production is less cost saving because the pest control is less efficient compared to the use of GMO (Fernandez-Cornejo and Caswell, 2006). In the restaurant case, using the fresh food is less cost saving in time and personnel compare to the frozen food, while it is unanimously preferred by consumers.

There is no information problem in the upstream market: each producer knows perfectly the quality $q_{i}$ supplied by the firm $(i \in\{1,2\})$. Without loss of generality, we assume that the low quality product is the product 1 and the high quality product is the product $2\left(q_{1}<q_{2}\right)$. Two environments are considered for the downstream market. In the labeled environment, a certifying public organization allows each producer that uses the input 2 to identify itself by a label for free. In the unlabeled environment, consumers cannot differentiate the quality of final product. ${ }^{6}$ We assume that each consumer believes that the final product is of low quality, $q_{1}$ (i.e. using input 1). This situation is characterized by a lemon problem (Akerlof, 1970): without information about upstream demand and supply, consumers can only anticipate that all producers will choose the more cost-saving input. Alternative specification of this consumer belief will be considered in Section 5 .

Table 1. Consumer and producer surplus

\begin{tabular}{c|c|c}
\hline & Unlabeled environment & Labeled environment \\
\hline Producer surplus & $\pi_{i}(\omega)=p-r_{i}-\omega q_{i}$ & $\pi_{i}(\omega)=p_{i}-r_{i}-\omega q_{i}$ \\
Consumer utility & $U(\theta)=\theta q_{1}-p$ & $U_{i}(\theta)=\theta q_{i}-p_{i}$ \\
\hline
\end{tabular}

The surplus of the producer and the consumer in both the labeled and unlabeled environments are defined in Table 1. $r_{i}$ and $p_{i}$ are, respectively, the price in the upstream and the downstream market. Consumers are uniformly distributed along a taste parameter $\theta \in[0, \bar{\theta}]$ such as the market is uncovered. Producers are uniformly distributed along a cost parameter $\omega \in[0, \bar{\omega}]{ }^{7}$ The mass of

\footnotetext{
${ }^{6}$ We assume that the production of low quality cannot be punished so that no producer can build reputation as in the case of experience goods. This is for example the case when consumers do not know the quality of the good bought even after consumption (see e.g. Darby and Karni, 1973, Garella and Petrakis, 2008, or Bonroy and Constantatos, 2008), or when the purchase relationship is not repeated.

${ }^{7}$ In the GMO example, $\omega q_{i}$ represents the cost of pests due to the yield loss. If we consider that $\omega$ captures the pest pressure level, it is coherent to suppose that farmers are heterogeneous with respect to this parameter because
} 
both producer and consumer populations is normalized to one. Consumers (respectively producers) choose the product that provides them with the highest surplus and do not consume (respectively produce) if this surplus is negative. The input quality is exogenous and upstream production costs are identical and normalized to 0 .

The decision sequence corresponds to a two-stage game. At stage 1, the upstream firms choose the input prices $r_{i}$ simultaneously, in a Bertrand game. At stage 2, all downstream producers and consumers act as price takers, so that the downstream equilibrium price $p_{i}$ equalizes supply to demand.

\section{Equilibrium on downstream and upstream markets}

- Equilibrium on the downstream market (stage 2). We first present the unlabeled environment, followed by the labeled one. These solutions enable us to establish the demand function on the upstream market, that we then use to solve stage 1 of the game.

In the absence of labeling, only one product is sold in the downstream market. Demand and supply functions are, respectively, $D(p)=\frac{1}{\bar{\theta}}\left(\bar{\theta}-\frac{p}{q_{1}}\right)$ and $S(p)=S_{1}(p)+S_{2}$, with:

$$
\left\{\begin{array}{l}
S_{1}(p)=\frac{1}{\bar{\omega}}\left(\frac{p-r_{1}}{q_{1}}-\frac{r_{1}-r_{2}}{q_{2}-q_{1}}\right) \\
S_{2}=\frac{1}{\bar{\omega}}\left(\frac{r_{1}-r_{2}}{q_{2}-q_{1}}\right)
\end{array}\right.
$$

Only producers with $\omega<\frac{p-r_{1}}{q_{1}}$ remain active and, among them, those with $\omega>\frac{r_{1}-r_{2}}{q_{2}-q_{1}}$ choose the input 1 while the others choose input 2 . The price of the downstream product is determined by equating $D(p)$ to $S(p)$ which yields $p=\frac{r_{1} \bar{\theta}+q_{1} \bar{\theta} \bar{\omega}}{\bar{\theta}+\bar{\omega}} .8$ The demand functions on the upstream market are therefore:

$$
\left\{\begin{array}{l}
S_{1}\left(r_{1}, r_{2}\right)=\frac{1}{\bar{\omega}}\left(\frac{q_{1} \bar{\theta} \bar{\omega}-r_{1} \bar{\omega}}{q_{1}(\bar{\theta}+\bar{\omega})}-\frac{r_{1}-r_{2}}{q_{2}-q_{1}}\right) \\
S_{2}\left(r_{1}, r_{2}\right)=\frac{1}{\bar{\omega}}\left(\frac{r_{1}-r_{2}}{q_{2}-q_{1}}\right)
\end{array}\right.
$$

We now consider the labeled environment: the two products are differentiated on the downstream market and their quality is known by consumers. ${ }^{9}$ It can easily be shown that consumers

pest pressure level is known to vary significantly among farms. It is recognized that GMOs are more valuable on farms with high pest pressure (Fernandez-Cornejo and Caswell, 2006). In the restaurants exemple, $\omega q_{i}$ represents the cost for preparing a meal and $\omega$ captures the heterogenity of restaurants (ability of staff to prepare meals).

${ }^{8}$ Note that, as a consequence of the market atomicity assumption, the high-quality producers do not use a lower price to signal the true quality. Only one price level in the downstream market is possible at the equilibrium.

${ }^{9}$ It can be observe that, because labeling is free for the producers, those who choose the input 2 cannot lose from adopting the label. So the label environment equilibrium is the same whatever the type of public label: voluntary or mandatory. 
prefer product 2 if $\theta>\frac{p_{2}-p_{1}}{q_{2}-q_{1}}$ and product 1 otherwise, and that all consumers with $\theta<\frac{p_{1}}{q_{1}}$ refrain from buying. Similarly, producers prefer the product 1 if $\omega>\frac{\left(p_{2}-p_{1}\right)-\left(r_{2}-r_{1}\right)}{q_{2}-q_{1}}$ and product 2 otherwise, and all producers with $\omega>\frac{p_{1}-r_{1}}{q_{1}}$ refrain from producing. Hence, the demand functions are:

$$
\left\{\begin{array}{l}
D_{1}\left(p_{1}, p_{2}\right)=\frac{1}{\bar{\theta}}\left(\frac{p_{2}-p_{1}}{q_{2}-q_{1}}-\frac{p_{1}}{q_{1}}\right) \\
D_{2}\left(p_{1}, p_{2}\right)=\frac{1}{\bar{\theta}}\left(\bar{\theta}-\frac{p_{2}-p_{1}}{q_{2}-q_{1}}\right)
\end{array}\right.
$$

and the supply functions are:

$$
\left\{\begin{array}{l}
S_{1}\left(p_{1}, p_{2}\right)=\frac{1}{\bar{\omega}}\left(\frac{p_{1}-r_{1}}{q_{1}}-\frac{\left(p_{2}-p_{1}\right)-\left(r_{2}-r_{1}\right)}{q_{2}-q_{1}}\right) \\
S_{2}\left(p_{1}, p_{2}\right)=\frac{1}{\omega}\left(\frac{\left(p_{2}-p_{1}\right)-\left(r_{2}-r_{1}\right)}{q_{2}-q_{1}}\right)
\end{array}\right.
$$

Both downstream prices are determined by equating $D_{2}\left(p_{1}, p_{2}\right)$ to $S_{2}\left(p_{1}, p_{2}\right)$ and $D_{1}\left(p_{1}, p_{2}\right)$ to $S_{1}\left(p_{1}, p_{2}\right)$. The derived demand functions on the upstream market are determined by introducing the output prices in Equation 2 and are given by:

$$
\left\{\begin{array}{l}
S_{1}\left(r_{1}, r_{2}\right)=\frac{1}{\bar{\theta}+\bar{\omega}}\left(\frac{r_{2}-r_{1}}{q_{2}-q_{1}}-\frac{r_{1}}{q_{1}}\right) \\
S_{2}\left(r_{1}, r_{2}\right)=\frac{1}{\bar{\theta}+\bar{\omega}}\left(\bar{\theta}-\frac{r_{2}-r_{1}}{q_{2}-q_{1}}\right)
\end{array}\right.
$$

- Equilibrium on the upstream market (stage 1). On the upstream market, firm $i(i=1,2)$ solves the following maximization problem: ${ }^{10}$

$$
\max _{r_{i}} \Pi_{i}=r_{i} S_{i}\left(r_{i}, r_{j}\right)
$$

Let the superscript $U$ indicate unlabeled-equilibrium values. The unlabeled upstream prices are given by:

$$
r_{1}^{U}=\frac{2 q_{1}\left(q_{2}-q_{1}\right) \bar{\theta} \bar{\omega}}{4 q_{2} \bar{\omega}+q_{1}(3 \bar{\theta}-\bar{\omega})} \quad \text { and } \quad r_{2}^{U}=\frac{q_{1}\left(q_{2}-q_{1}\right) \bar{\theta} \bar{\omega}}{4 q_{2} \bar{\omega}+q_{1}(3 \bar{\theta}-\bar{\omega})}
$$

Since the final products are undifferentiated in the downstream market, the low-quality product is more cost saving and, consequently, priced at a higher level compared to the high-quality product.

The equilibrium output price is:

$$
p^{U}=\frac{q_{1} \bar{\theta} \bar{\omega}\left(\left(2 q_{2}+q_{1}\right) \bar{\theta}+\left(4 q_{2}-q_{1}\right) \bar{\omega}\right)}{(\bar{\theta}+\bar{\omega})\left(4 q_{2} \bar{\omega}+q_{1}(3 \bar{\theta}-\bar{\omega})\right)}
$$

As the upstream market is differentiated, each firm and each active producer has a positive profit. Note that when producers are homogenous (i.e. $\bar{\omega}=0$ ), both output and input are sold at

\footnotetext{
${ }^{10}$ Only linear pricing can be concidered here because each producer purchases either 0 or 1 unit of input.
} 
marginal cost so that no firms and no producers make a positive profit. The downstream market is then a competitive market characterized by a constant marginal cost, and the upstream market is a duopoly market characterized by the Bertrand paradox.

Let a superscript $L$ indicate labeled equilibrium values. The labeled equilibrium input prices are given by:

$$
r_{1}^{L}=\frac{\left(q_{2}-q_{1}\right) q_{1} \bar{\theta}}{4 q_{2}-q_{1}} \quad \text { and } \quad r_{2}^{L}=\frac{2\left(q_{2}-q_{1}\right) q_{2} \bar{\theta}}{4 q_{2}-q_{1}}
$$

while output prices are:

$$
p_{1}^{L}=q_{1} \bar{\theta} \frac{\left(q_{2}-q_{1}\right) \bar{\theta}+\left(4 q_{2}-q_{1}\right) \bar{\omega}}{\left(4 q_{2}-q_{1}\right)(\bar{\theta}+\bar{\omega})} \quad \text { and } \quad p_{2}^{L}=q_{2} \bar{\theta} \frac{2\left(q_{2}-q_{1}\right) \bar{\theta}+\left(4 q_{2}-q_{1}\right) \bar{\omega}}{\left(4 q_{2}-q_{1}\right)(\bar{\theta}+\bar{\omega})}
$$

At equilibrium, the price of the labeled product on the downstream market is higher compared to the price of the non-labeled product.

Unlike the unlabeled environment, when producers are homogenous (i.e. $\bar{\omega}=0$ ) upstream firms have a positive profit. As the downstream market is differentiated, upstream firms may differentiate their product and earn the same positive profits as in a vertically differentiated duopoly model without intermediary producers (see Wauthy, 1996).

\section{Consequences of a label}

In this section we investigate the economic consequences on the markets when the downstream producers can adopt a label. We start by analyzing the consequences on the upstream market by looking first at the equilibrium prices and quantities (Lemma 1) and then at the upstream firms profits (Proposition 1).

Lemma $1 r_{1}^{U}>r_{2}^{U} ; r_{2}^{L}>r_{1}^{L} ; r_{2}^{L}>r_{2}^{U} ; r_{1}^{L}<r_{1}^{U}$ iff $\frac{\bar{\omega}}{\bar{\theta}}>k_{1} \equiv \frac{3 q_{1}}{4 q_{2}-q_{1}} ; S_{1}^{L}<S_{1}^{U} ; S_{2}^{L}>S_{2}^{U}$; $S^{L}>S^{U}$ iff $\overline{\bar{\theta}}>k_{1}$.

Proof. See Appendix 1.

Two major effects explain the input price variation caused by the labeling. First, products are differentiated in both the upstream and downstream markets instead of only in the upstream market. As in a standard vertical differentiation model, information about quality differences tends to increase the price of each product (see Gabszewicz and Thisse, 1979, and Shaked and Sutton, 1982). We call this first effect "differentiation effect". Second, the label affects product ranking. Without labeling the final product is undifferentiated. All producers therefore prefer low-quality 
input for cost-saving reasons. As a result, the price of the lower-quality input is higher $\left(r_{1}^{U}>r_{2}^{U}\right)$. By signaling the qualities in the downstream market, the label reverses product ranking since all active producers will then prefer the high-quality input, despite its higher cost. ${ }^{11}$ Hence, at equilibrium we have $r_{2}^{L}>r_{1}^{L}$. We call this second effect "ranking effect".

Both effects positively affect the high-quality upstream price. A better valorization of the highquality product leads, unsurprisingly, to an increase of the corresponding input price, i.e. $r_{2}^{L}>r_{2}^{U}$. More interestingly, these effects affect the low-quality upstream-price in opposite directions. As for the high-quality input price, the differentiation effect is positive. But, on the other hand, the ranking effect is negative. Finally, when these two effects are added, we find that the ranking effect dominates the differentiation effect $\left(r_{1}^{L}<r_{1}^{U}\right)$ if the ratio $\frac{\bar{\omega}}{\bar{\theta}}$ is high enough. In an unlabeled environment with a high level of $\bar{\omega}$, the low-quality firm wants to exploit producers with a high willingness to pay for the low-quality product, and charge a high price. As a result, when the qualities are known, if heterogeneity among consumers is not sufficiently high, the differentiation effect is dominated by the ranking effect: Firm 1 cannot avoid decreasing its price.

In summary, the heterogeneity of the producers relative to the consumers $\left(\frac{\bar{\omega}}{\bar{\theta}}\right)$ is the determinant in balancing the differentiation and the ranking effects on the low-quality input price. On the one hand, higher heterogeneity of consumers $(\bar{\theta})$ increases the differentiation effect by relaxing competition with labeling. On the other hand, higher producer heterogeneity $(\bar{\omega})$ relaxes competition without labeling and leads to a more important ranking effect because of the higher input price $\left(r_{1}^{U}\right)$. We can observe that the ratio $\frac{\bar{\omega}}{\bar{\theta}}$ is also an indicator of the price elasticity of the supply relative to the price elasticity of the demand, both on the downstream market. As this ratio increases, the share of producer surplus relative to the sum of the producers and consumers surplus increases.

Proposition 1 The high-quality firm always benefits from labeling. The low-quality firm is hurt by labeling iff $\frac{\overline{\bar{\theta}}}{\bar{\theta}}>k_{2} \equiv \frac{q_{1}\left(2 \sqrt{13 q_{2}^{2}-5 q_{1} q_{2}+q_{1}^{2}}-5 q_{2}+2 q_{1}\right)}{3 q_{2}\left(4 q_{2}-q_{1}\right)}$.

Proof. See Appendix 2.

In a standard vertical product differentiation model, labeling is desirable for all firms. The revelation of the true product quality allows the high-quality firm to extract more surplus from customers with higher willingness to pay for quality, while also leaving room for the lower-quality firm. The price competition is relaxed, and both firms enjoy superior profits. In the vertical structure considered in this paper, this result is not always true. As we saw in Lemma 1, labeling

\footnotetext{
${ }^{11}$ It is easy to show that when both inputs are priced to marginal costs $\left(r_{2}^{L}=r_{1}^{L}=0\right)$, all active producers (i.e. characterized by an $\omega<\frac{p_{1}^{L}-r_{1}^{L}}{q_{1}}$ ) prefer the high-quality input.
} 
leads to a decrease of the price of the low-quality input if the ranking effect is strong enough. The low-quality firm is then always hurt by the label $\left(\frac{\bar{w}}{\bar{\theta}}>k_{2} \text { is always respected }\right)^{12}$. Conversely, an increase of the low-quality input price is a necessary but not sufficient condition for the lowquality upstream supplier to gain. The low-quality firm gains from labeling if the price increase is sufficiently high to compensate the loss of consumers. Finally, as in a standard vertical product differentiation model, the high-quality firm always benefits from labeling.

We now investigate the economic consequences of labeling on the downstream market.

Lemma $2 p_{1}^{L}<p^{U}$ iff $\frac{\bar{\omega}}{\bar{\theta}}>k_{1} ;\left|p_{1}^{L}-p^{U}\right|<\left|r_{1}^{L}-r_{1}^{U}\right| ; p_{2}^{L}>p^{U}$ and $p_{2}^{L}-p^{U}>r_{2}^{L}-r_{2}^{U}$

Proof. See Appendix 3.

Recall that labeling enables to differentiate the two products on the downstream market: the high-quality product for which consumers have a greater willingness to pay, and the low-quality product for which consumers have the same willingness to pay compared to the product sold without label. The higher willingness to pay for the high-quality product leads, unsurprisingly, to an increase of its price $\left(p_{2}^{L}>p^{U}\right)$. As observed before (lemma 1) the price of the corresponding input increases, but this increase does not cover the output price increase. For the low-quality product, the producers face the same demand curve because the consumers have the same propensity to pay for their production. The downstream price equilibrium after labeling depends only on the variation of the production cost (i.e. input cost): the downstream price increases $\left(p_{1}^{L}>p^{U}\right)$ if and only if the corresponding input price also increases $\left(r_{1}^{L}>r_{1}^{U}\right)$. The labeling leads to a parallel shift of the low-quality supply curve, and the equilibrium price variation from this shift does not cover the variation of the production cost $\left(\left|p_{1}^{L}-p^{U}\right|<\left|r_{1}^{L}-r_{1}^{U}\right|\right)$. Therefore the effect of labeling on the low-quality product is similar to a subsidy (if $\frac{\overline{\bar{\theta}}}{\bar{\theta}}>k_{1}$ ) or a tax (if $\frac{\overline{\bar{\omega}}}{\bar{\theta}}<k_{1}$ ).

In summary, labeling enables the high-quality firm to differentiate its product from the lowquality product, and leads to an upward shift of its demand curve by consumers. This shift leads to an increase of the output price which is partially transmitted to the input price. As a result, the low-quality input price may increase or decrease, and this variation in the production cost is partially transmitted to the output price.

Proposition 2 Each active intermediary producer and active final consumer gains from labeling if $\frac{\overline{\bar{\theta}}}{\bar{\theta}}>k_{1}$. Otherwise, only those who produce or consume the labeled product can be better off.

$$
{ }^{12} k_{1}-k_{2}=\frac{2 q_{1}\left(7 q_{2}-q_{1}-\sqrt{13 q_{2}^{2}-5 q_{1} q_{2}+q_{1}^{2}}\right)}{3 q_{2}\left(4 q_{2}-q_{1}\right)}>0 .
$$


Proof. See Appendix 4.

This proposition studies the impact of labeling on each producer and consumer. The main result is that each of them gains from labeling if the low-quality input price decreases (i.e. if the ranking effect dominates the differentiation effect). A more detailed analysis requires a separate analysis of the different categories of producers and consumers according to their choice in both unlabeled and labeled environments (see Figures 1 and 2).

Some categories always gain from labeling. Consumers who, under labeling, choose the highquality product generally gain from an increase in the quality despite a higher price. In the same way, the producers who choose the high-quality input in both environments gain because the output price increase is not covered by the input price increase (cf. Lemma 2). In summary, the producers and consumers who are part of the high-quality supply chain always gain from labeling. Nevertheless, a few marginal producers and consumers may be an exception to this rule, e.g. some high-quality consumers with a relatively low willingness to pay and some producers that switch from the input 1 to the input 2 (see areas $U \rightarrow 2$ in Figure 2 and $1 \rightarrow 2$ in Figure 1 ).

The producers and consumers who are not part of the high-quality supply chain benefit from labeling only if the low-quality input price decreases. Recall that, when comparing the two unlabeled and labeled environments, the consumers have the same willingness to pay for the product $\left(\theta q_{1}\right)$, and the variations in prices of both the low-quality input and output have the same sign. Hence the variation of utility or profit for these actors only depends on the variation of low-quality input price, which are similar to the effects of a tax or a subsidy. In summary, if the input price increases (i.e. if $\frac{\bar{\omega}}{\bar{\theta}}<k_{1}$ ), some producers and consumers lose by leaving the markets, the low-quality consumers lose because they consume the same product at a higher price, and the low-quality producers lose because the output price increase does not cover the input price increase (cf. Lemma 2). Conversely, if the input price decreases (i.e. if $\frac{\bar{\omega}}{\bar{\theta}}>k_{1}$ ), some producers and consumers gain by entering into the markets, the low-quality consumers gain because they consume the same product at a lower price, and the low-quality producers gain because the input price decrease is not covered by the output price decrease (cf. Lemma 2). This result contrasts with the standard result that more differentiation generally hurts consumers with lower willingness to pay for quality.

Propositions 1 and 2 provide interesting insights concerning the economic consequences of the adoption of a label by the high-quality producers. On the one hand, the revelation of the product quality generates positive externalities on the other actors (the upstream firm and the consumers) of the high-quality supply chain. On the other hand, the adoption of the label can creates a tension between the upstream and the downstream actors within the low-quality supply chain. 
This tension depends on the magnitude of the differentiation and ranking effect described before. If $\frac{\bar{w}}{\bar{\theta}}<k_{2}$, the differentiation effect is sufficiently large that the upstream low-quality firm benefits from the label, while the producers and the consumers are worse off. Indeed labeling leads to a less intensive competition among the upstream firms, such that the low-quality input price increases, which is like a tax for the downstream actors. Conversely, if $\frac{\bar{\omega}}{\bar{\theta}}>k_{1}$, the ranking effect dominates and the low-quality input price decreases: the upstream firm loses profit and the label acts on the low-quality output production as a subsidy. Between these two extreme situations, there is a set of parameters values $\left(k_{2}<\frac{\bar{\omega}}{\bar{\theta}}<k_{1}\right)$ such that the label is detrimental to all the actors of the low-quality supply chain.

We now study the aggregate impact of labeling. As in a standard vertical product differentiation model, enabling the differentiation is always welfare improving. Then, a government has always interest to implement a label. The last proposition below analyzes the surplus variation of the downstream actors (producers and consumers) taken all together.

Proposition 3 Collectively, all intermediary producers gain from labeling iff $\frac{\bar{w}}{\bar{\theta}}>k_{3}$, and all final consumers gain from labeling iff $\frac{\bar{\omega}}{\bar{\theta}}>k_{4}$. As $k_{3}>k_{4}$, all consumers gain from labeling when all intermediary producers gain from labeling.

Proof. See Appendix 5.

As we saw in the Proposition 2, some of the producers or consumers individually lose from labeling if the low-quality input price increases. Proposition 3 defines the threshold values of $\frac{\bar{w}}{\bar{\theta}}$ such as the collective downstream surplus is positively or negatively affected by the label. We find that when the differentiation effect strongly dominates the ranking effect $\left(\frac{\bar{\omega}}{\bar{\theta}}<k_{4}\right)^{13}$, labeling decreases without ambiguity the downstream surplus. This result shows an interesting outcome of labeling: when the ranking effect is not sufficiently large, a governmental label fails to improve the surplus of downstream actors. The gain of the high-quality downstream actors is not sufficient to cover the loss of the low-quality downstream actors. In this case, the positions of downstream actors and government about the labeling differ: the downstream part of supply chain do not want the label while it improves the social welfare.

\section{Extensions}

We first discuss our assumption on consumers' beliefs in the unlabeled environment. Recall that, in our basic model, having no information about the upstream market, consumers believe that all

${ }^{13} k_{1}>k_{2}>k_{3}>k_{4}$ (see Figure 3 ). 
producers choose the more cost-saving input. As a result they expect the low quality $\left(q_{e}=q_{1}\right)$. However, consumers may better anticipate the real proportion of each quality and expect a quality between $q_{1}$ and $q_{2}$. We consider here an alternative specification where the consumers perfectly anticipate the proportion of each quality and expect an average quality weighted by the market share of each product: $q_{e}=\alpha q_{1}+(1-\alpha) q_{2}$ where $\alpha$ is the endogenous proportion of the low-quality product. The main difference with our basic model is that the consumer's willingness to pay for the low-quality product in the labeled environment is lower than for the expected quality $\left(\theta q_{1}<\theta q_{e}\right)$. This change affects the price variation between the expected-quality product and the low-quality product $\left(p_{1}^{L}-p^{U}\right)$. In the basic model this price variation depends only on the low-quality inputprice variation $\left(r_{1}^{L}-r_{1}^{U}, c f\right.$. lemma 2$)$ while, in this extension, this price variation is also affected by the shift of the demand function of consumers with low taste parameter. Despite this difference, this extension does not qualitatively modify our main results summarized in Propositions 1 to $3 .{ }^{14}$ The threshold values on the $\frac{\bar{w}}{\bar{\theta}}$ are different but are ordered similarly. For example, with $q_{1}=1 / 2$, $q_{2}=1$ and $\bar{\theta}=1, r_{1}^{L}<r_{1}^{U}$ iff $\bar{\omega}>0.282, \Pi_{1}^{L}<\Pi_{1}^{U}$ iff $\bar{\omega}>0.106$ and $S C^{L}>S C^{U}$ iff $\bar{\omega}>0.023 .{ }^{15}$ As in our basic model, if $\bar{\omega}$ is large enough, the ranking effect dominates the differentiation effect so that low-quality input price decreases, the profit of the low-quality firm also decreases, and all producers and consumers are better off. Note that, unlike the basic model, conditions such as $r_{1}^{L}<r_{1}^{U}$ and $p_{1}^{L}<p^{U}$ are not the same: $p_{1}^{L}<p^{U}$ iff $\bar{\omega}>0.236$ and $r_{1}^{L}<r_{1}^{U}$ iff $\bar{\omega}>0.282$.

The market configuration so far is an uncovered market because the lower bound of the consumer taste parameter $(\underline{\theta})$ is equal to 0 . Assuming a covered market makes the analysis more complex because it leads to a continuum of downstream price equilibria ${ }^{16}$ but otherwise leaves our main results qualitatively unmodified. The only exception concerns the impact of labeling on downstream actors, which depends on the downstream price equilibrium considered. ${ }^{17}$ For example, when the downstream price equilibrium is such that the participation constraint of the consumer described by $\underline{\theta}$ is binding, then the low-quality downstream price is not affected by labeling $\left(p_{1}^{L}=p^{U}=q_{1} \underline{\theta}\right)$. In this case, the label does not hurt consumers, but producers may be worse off. Conversely, when the downstream price equilibrium is such that the participation constraint of the producer with $\bar{\omega}$ is binding, then the markup of the low-quality producer is not affected by the label $\left(p_{1}^{L}-r_{1}^{L}=p^{U}-r_{1}^{U}=q_{1} \bar{\omega}\right)$. Any variation of the low-quality input price is directly

\footnotetext{
${ }^{14}$ It is not possible to get any tractable analytic solution with this extension. Numeric resolutions were performed with Mathematica and comparative statics derived from multiple simulations.

${ }^{15}$ The computations are available from authors upon request.

${ }^{16}$ For example, in the unregulated environment, any downstream price $p \in\left[r_{1}+q_{1} \bar{\omega}, q_{1} \underline{\theta}\right]$ fulfills both covered market conditions $\left(\pi_{1}(\bar{\omega})>0\right.$ and $\left.U(\underline{\theta})>0\right)$, and is consequently an equilibrium.

${ }^{17}$ It is important to note that the choice of downstream equilibrium price affects only output prices and, consequently, the surplus sharing between producers and consumers. The upstream price and quality chosen by any producer or any final consumer are the same, irrespective of the downstream equilibrium price considered.
} 
transmitted to the low-quality output price. In this case, labeling does not hurt producers, but consumers may be worse off.

\section{Conclusion}

This article is a contribution to the literature on the economic impact of labeling. We focus here more particularly on strategic effects, by considering a simple framework with costless labeling and two vertically related markets. By solving an information problem on product quality in the downstream market, labeling has some indirect consequences on the competition in the upstream market. In particular, we show that the upstream market price competition is affected by a ranking effect by which the more cost-saving technology becomes less valuable because it leads to a lowquality product for the final consumer. The case of GMOs is a fine illustration of this framework. This technology is more cost-saving because it enables the farmer to control pests better, but consumers have a lower willingness to pay for the agricultural product when the farmer uses GMO seeds. The labeling of the GMO, as required by the European Union, affects the ranking of these technologies. The farmer considers not only the cost-saving attribute of the GMO but also the fact that its production will be sold at a lower price. Beyond this illustration, our analytical framework is applicable to a wide range of situations where downstream labeling affects the ranking of products in the upstream markets.

A standard strategic effect in the literature is that labeling softens competition by further differentiating the two products. This effect can however be dominated by the ranking effect so that labeling hurts the upstream supplier of the low-quality input to the benefit of the low-quality downstream actors. This phenomenon occurs in particular when the upstream competition is weaker in the unlabeled environment than in the labeled environment. This result improves our understanding of the effects of certain labels. It shows that public labeling of restaurants that use fresh and local ingredients may affect the low-quality restaurants like a subsidy, and it helps to explain Monsanto's opposition to the labeling of GMOs. ${ }^{18}$

\footnotetext{
${ }^{18}$ Monsanto takes a clear position against labeling, stating "to date, no approved biotech crop is either an allergen, or has any significant nutritional differences from non-GM counterparts", and consequently "requiring labeling for ingredients that don't pose a health issue would undermine both our labeling laws and consumer confidence." These citations are from Monsanto's web site: http://www.monsanto.com/monsanto_today/for_the_record/gmo_labeling.asp.

This opposition can also be explaine $\overline{-}$ by the fact that labeling could affect consumers' belief about the GMO quality increasing the perception of low quality.
} 


\section{Acknowledgements}

We are grateful to Eric Avenel, Christos Constantatos, Kai-Uwe Kühn, Jean-Philippe Tropéano, Norbert Wilson, participants to the AFIO seminar of the Toulouse School of Economics and to the 36th EARIE annual conference for their comments.

\section{References}

Akerlof, G. (1970). The Market for "Lemons"; Quality Uncertainty and the Market Mechanism. Quarterly Journal of Economics, 84(3), 488-500.

Bonroy, O., and Constantatos, C. (2008). On the Use of Labels in Credence Goods Markets. Journal of Regulatory Economics, 33(3), 237-252.

Darby, M., and Karni, E. (1973). Free Competition and the Optimal Amount of Fraud. Journal of Law and Economics, 16(1), 67-88.

Fernandez-Cornejo, J., and Caswell, M. (2006). The First Decade of Genetically Engineered Crops in the United States, USDA-ERS Economic Information Bulletin num 11 (http://www.ers. usda.gov/Publications/eib11/).

Fulton, M., and Giannakas, K. (2004). Inserting GM Products into the Food Chain: The Market and Welfare Effects of Different Labeling and Regulatory Regimes. American Journal of Agricultural Economics, 86(1), 42-60.

Gabszewicz, J. and Thisse, J. (1979). Price Competition, Quality and Income Disparities. Journal of Economics Theory, 20, 340-359.

Garella, P. G., and Petrakis, E. (2008). Minimum Quality Standards and Consumers' Information. Economic Theory, 36(2), 283-302.

Lapan, H., and Moschini, G. (2007). Grading, Minimum Quality Standards, and the Labeling of Genetically Modified Products. American Journal of Agricultural Economics, 89(3), 769-783.

Lusk, J. L., Jamal, M., Kurlander, L., Roucan, M., and Taulman, L. (2005). A Meta-Analysis of Genetically Modified Food Valuation Studies. Journal of Agricultural and Resource Economics, $30(1), 28-44$.

Marette, S. (2007). Minimum Safety Standard, Consumers' Information and Competition. Journal of Regulatory Economics, 32(3), 259-285.

Noussair, C., Robin, S., and Ruffieux B. (2004). Do Consumers Really Refuse To Buy Genetically Modified Food? The Economic Journal, 114(492), 102-120. 
Roe, R., and Sheldon, I. (2007). Credence Good Labeling: The Efficiency and Distributional Implications of Several Policy Approaches. American Journal of Agricultural Economics, 89(4), 1020-1033.

Shaked, A., and Sutton, J. (1982). Relaxing Price Competition through Product Differentiation. Review of Economic Studies, 49(1), 3-13.

Wauthy, X. (1996). Quality Choice in Models of Vertical Differentiation. Journal of Industrial Economics, $44(3), 345-353$. 


\section{Appendix}

Appendix 1: Proof Lemma 1.

$$
\begin{aligned}
& S_{1}^{L}-S_{1}^{U}=-\frac{1}{2} \bar{\theta}\left(\frac{\left(2 q_{2}-q_{1}\right)}{\left(4 q_{2}-q_{1}\right)(\bar{\theta}+\bar{\omega})}+\frac{q_{1}}{3 q_{1} \bar{\theta}+\left(4 q_{2}-q_{1}\right) \bar{\omega}}\right)<0, \\
& S_{2}^{L}-S_{2}^{U}=\frac{\bar{\theta}\left(\left(q_{1}^{2}+2 q_{1} q_{2}\right) \bar{\theta}+\left(8 q_{2}^{2}-6 q_{1} q_{2}+q_{1}^{2}\right) \bar{\omega}\right)}{\left(4 q_{2}-q_{1}\right)(\bar{\theta}+\bar{\omega})\left(3 q_{1} \bar{\theta}+\left(4 q_{2}-q_{1}\right) \bar{\omega}\right)}>0, \\
& S^{L}-S^{U}=\frac{\left(q_{2}-q_{1}\right) \bar{\theta}\left(\left(4 q_{2}-q_{1}\right) \bar{\omega}-3 q_{1} \bar{\theta}\right)}{\left(4 q_{2}-q_{1}\right)(\bar{\theta}+\bar{\omega})\left(3 q_{1} \bar{\theta}+\left(4 q_{2}-q_{1}\right) \bar{\omega}\right)}>0 \text { iff } \frac{\overline{\bar{\omega}}}{\bar{\theta}}>k_{1} \equiv \frac{3 q_{1}}{4 q_{2}-q_{1}}, \\
& r_{1}^{U}-r_{2}^{U}=r_{2}^{U}=\frac{q_{1}\left(q_{2}-q_{1}\right) \bar{\theta} \bar{\omega}}{4 q_{2} \bar{\omega}+q_{1}(3 \bar{\theta}-\bar{\omega})}, \\
& r_{2}^{L}-r_{1}^{L}=\frac{\left(q_{2}-q_{1}\right)\left(2 q_{2}-q_{1}\right) \bar{\theta}}{4 q_{2}-q_{1}}>0, \\
& r_{2}^{L}-r_{2}^{U}=\frac{\left(q_{2}-q_{1}\right) \bar{\theta}\left(6 q_{1} q_{2} \bar{\theta}+\left(8 q_{2}^{2}-6 q_{1} q_{2}+q_{1}^{2}\right) \bar{\omega}\right)}{\left(4 q_{2}-q_{1}\right)\left(3 q_{1} \bar{\theta}+\left(4 q_{2}-q_{1}\right) \bar{\omega}\right)}>0, \\
& \text { and } r_{1}^{L}-r_{1}^{U}=\frac{q_{1}\left(q_{2}-q_{1}\right) \bar{\theta}\left(3 q_{1} \bar{\theta}-\left(4 q_{2}-q_{1}\right) \bar{\omega}\right)}{\left(4 q_{2}-q_{1}\right)\left(3 q_{1} \bar{\theta}+\left(4 q_{2}-q_{1}\right) \bar{\omega}\right)}>0 \text { iff } \frac{\bar{\omega}}{\bar{\theta}}<k_{1} .
\end{aligned}
$$

Appendix 2: Proof Proposition 1.

$$
\begin{aligned}
\Pi_{2}^{L}- & \Pi_{2}^{U}=\frac{\left(q_{2}-q_{1}\right) \bar{\theta}^{2}\left(36 q_{1}^{2} q_{2}^{2} \bar{\theta}^{2}+q_{1}\left(4 q_{2}-q_{1}\right)\left(24 q_{2}^{2}-4 q_{1} q_{2}+q_{1}^{2}\right) \bar{\theta} \bar{\omega}+\left(4 q_{2}-q_{1}\right)^{2}\left(4 q_{2}^{2}-q_{1}^{2}\right) \bar{\omega}^{2}\right)}{\left(4 q_{2}-q_{1}\right)^{2}(\bar{\theta}+\bar{\omega})\left(3 q_{1} \bar{\theta}+\left(4 q_{2}-q_{1}\right) \bar{\omega}\right)^{2}}>0, \\
\Pi_{1}^{L}-\Pi_{1}^{U} & =\frac{\left(q_{2}-q_{1}\right) q_{1} \bar{\theta}^{2}\left(9 q_{1}^{2} q_{2} \bar{\theta}^{2}-2 q_{1}\left(5 q_{2}-2 q_{1}\right)\left(4 q_{2}-q_{1}\right) \bar{\theta} \bar{\omega}-3\left(4 q_{2}-q_{1}\right)^{2} q_{2} \bar{\omega}^{2}\right)}{\left(4 q_{2}-q_{1}\right)^{2}(\bar{\theta}+\bar{\omega})\left(3 q_{1} \bar{\theta}+\left(4 q_{2}-q_{1}\right) \bar{\omega}\right)^{2}}>0 \\
\text { iff } \bar{\omega} & <\frac{2 \sqrt{q_{1}^{2}\left(4 q_{2}-q_{1}\right)^{2}\left(13 q_{2}^{2}-5 q_{1} q_{2}+q_{1}^{2}\right) \bar{\theta}^{2}-q_{1}\left(5 q_{2}-2 q_{1}\right)\left(4 q_{2}-q_{1}\right) \bar{\theta}}}{3 q_{2}\left(4 q_{2}-q_{1}\right)^{2}}, \\
\text { i.e. } \overline{\bar{\theta}} & <k_{2} \equiv \frac{q_{1}\left(2 \sqrt{\left.13 q_{2}^{2}-5 q_{1} q_{2}+q_{1}^{2}-5 q_{2}+2 q_{1}\right)}\right.}{3 q_{2}\left(4 q_{2}-q_{1}\right)}>0 .
\end{aligned}
$$

Appendix 3: Proof Lemma 2.

$$
\begin{aligned}
& p_{1}^{L}-p^{U}=\frac{\left(q_{2}-q_{1}\right) q_{1} \bar{\theta}^{2}\left(3 q_{1} \bar{\theta}-\left(4 q_{2}-q_{1}\right) \bar{\omega}\right)}{\left(4 q_{2}-q_{1}\right)(\bar{\theta}+\bar{\omega})\left(3 q_{1} \bar{\theta}+\left(4 q_{2}-q_{1}\right) \bar{\omega}\right.}>0 \text { iff } \frac{\bar{\omega}}{\bar{\theta}}<k_{1}, \\
& \left|p_{1}^{L}-p^{U}\right|<\left|r_{1}^{L}-r_{1}^{U}\right| \text { iff }\left|\bar{\theta}\left(3 q_{1} \bar{\theta}-\left(4 q_{2}-q_{1}\right) \bar{\omega}\right)\right|<\left|(\bar{\theta}+\bar{\omega})\left(3 q_{1} \bar{\theta}-\left(4 q_{2}-q_{1}\right) \bar{\omega}\right)\right| \text { that is always }
\end{aligned}
$$
true.

$$
\begin{aligned}
& p_{2}^{L}-p^{U}=\frac{\left(q_{2}-q_{1}\right) \bar{\theta}\left(6 q_{1} q_{2} \bar{\theta}^{2}+\left(4 q_{2}-q_{1}\right)\left(2 q_{2}+q_{1}\right) \bar{\theta} \bar{\omega}+\left(4 q_{2}-q_{1}\right)^{2} \bar{\omega}^{2}\right)}{\left(4 q_{2}-q_{1}\right)(\bar{\theta}+\bar{\omega})\left(3 q_{1} \bar{\theta}+\left(4 q_{2}-q_{1}\right) \bar{\omega}\right.}>0, \\
& \left(p_{2}^{L}-p^{U}\right)-\left(r_{2}^{L}-r_{2}^{U}\right)=\frac{2\left(q_{2}-q_{1}\right) \bar{\theta} \bar{\omega}\left(q_{1}\left(q_{2}-q_{1}\right) \bar{\theta}+\left(4 q_{2}-q_{1}\right) q_{2} \bar{\omega}\right)}{\left(4 q_{2}-q_{1}\right)(\bar{\theta}+\bar{\omega})\left(3 q_{1} \bar{\theta}+\left(4 q_{2}-q_{1}\right) \bar{\omega}\right.}>0
\end{aligned}
$$

Appendix 4: Proof Proposition 2.

i) Impact on surplus of each producer:

Let us first consider the producers who choose the same input in both unlabeled and labeled environments. Producers who choose the high-quality product always gain from labeling: $\left(p_{2}^{L}-r_{2}^{L}\right)-\left(p^{U}-r_{2}^{U}\right)=\frac{2\left(q_{2}-q_{1}\right) \bar{\theta} \bar{\omega}\left(q_{1}\left(q_{2}-q_{1}\right) \bar{\theta}+\left(4 q_{2}-q_{1}\right) q_{2} \bar{\omega}\right)}{\left(4 q_{2}-q_{1}\right)(\bar{\theta}+\bar{\omega})\left(3 q_{1} \bar{\theta}+\left(4 q_{2}-q_{1}\right) \bar{\omega}\right.}>0$; and producers who choose 
the low quality product gain from labeling iff $\frac{\overline{\bar{\theta}}}{\bar{\theta}}$ is sufficiently high: $\left(p_{1}^{L}-r_{1}^{L}\right)-\left(p^{U}-r_{1}^{U}\right)=$ $\frac{q_{1}\left(q_{2}-q_{1}\right) \bar{\theta} \bar{\omega}\left(\left(4 q_{2}-q_{1}\right) \bar{\omega}-3 q_{1} \bar{\theta}\right)}{\left(4 q_{2}-q_{1}\right)(\bar{\theta}+\bar{\omega})\left(3 q_{1} \bar{\theta}+\left(4 q_{2}-q_{1}\right) \bar{\omega}\right.}>0$ iff $\frac{\bar{\omega}}{\bar{\theta}}>k_{1}$.

Producers that switch from the low to the high quality may be worse off only when $\frac{\bar{w}}{\bar{\theta}}<k_{1}$ and for sufficiently high $\omega$ producers (see Figure 1 for a graphic representation).

ii) Impact on surplus of each consumer:

Lemma 1 and 2 show that when $\frac{\bar{\omega}}{\bar{\theta}}>k_{1}$ then $S^{L}>S^{U}$ and $p_{1}^{L}<p^{U}$. It follows that when $\frac{\bar{\omega}}{\bar{\theta}}>k_{1}$ more consumers participate in the market and low-quality consumers are better off (and conversely).

Consumers of high-quality labeled product always gain if $\frac{\bar{\omega}}{\bar{\theta}}>k_{1}$ (otherwise they would gain by choosing low quality). Whenever $\frac{\overline{\bar{\omega}}}{\bar{\theta}}<k_{1}$, some of them with low $\theta$ may be worse off (see Figure 2 for a graphic representation).

Appendix 5: Proof Proposition 3.

i) The impact of label on producers' surplus is given by: ${ }^{19}$

$$
\begin{aligned}
& \pi^{L}-\pi^{U}=\frac{\left(q_{2}-q_{1}\right) \bar{\theta}^{2} \bar{\omega}\left(q_{1}^{2}\left(8 q_{1}^{2}-55 q_{2} q_{1}+20 q_{2}^{2}\right) \bar{\theta}^{2}-2 q_{1}\left(4 q_{2}-q_{1}\right)\left(2 q_{1}^{2}+q_{2} q_{1}-12 q_{2}^{2}\right) \bar{\theta} \bar{\omega}+\left(4 q_{2}-q_{1}\right)^{2} q_{2}\left(4 q_{2}+5 q_{1}\right) \bar{\omega}^{2}\right)}{2\left(4 q_{2}-q_{1}\right)^{2}(\bar{\theta}+\bar{\omega})^{2}\left(3 q_{1} \bar{\theta}+\left(4 q_{2}-q_{1}\right) \bar{\omega}\right)^{2}} \\
& \pi^{L}-\pi^{U}>0 \text { iff } \frac{\bar{\omega}}{\bar{\theta}}>k_{3} \equiv \frac{q_{1}\left(2 q_{1}^{2}+q_{2} q_{1}-12 q_{2}^{2}+2 \sqrt{16 q_{2}^{4}+24 q_{2}^{3} q_{1}+49 q_{2}^{2} q_{1}^{2}-9 q_{2} q_{1}^{3}+q_{1}^{4}}\right)}{\left(4 q_{2}-q_{1}\right) q_{2}\left(4 q_{2}+5 q_{1}\right)}
\end{aligned}
$$

ii) The impact of label on consumers surplus is given by: $:^{20}$

$$
\begin{aligned}
& S C^{L}-S C^{U}=\frac{\left(q_{2}-q_{1}\right) q_{2} \bar{\theta}^{3}\left(-3 q_{1}\left(3 q_{1}-2 q_{2}\right) \bar{\theta}+\left(4 q_{2}-q_{1}\right)\left(2 q_{2}+3 q_{1}\right) \bar{\omega}\right)}{\left(4 q_{2}-q_{1}\right)^{2}(\bar{\theta}+\bar{\omega})^{2}\left(3 q_{1} \bar{\theta}+\left(4 q_{2}-q_{1}\right) \bar{\omega}\right)} \\
& S C^{L}-S C^{U}>0 \text { iff } \frac{\bar{\omega}}{\overline{\bar{\theta}}}>k_{4} \equiv \frac{3 q_{1}\left(3 q_{1}-2 q_{2}\right)}{\left(4 q_{2}-q_{1}\right)\left(2 q_{2}+3 q_{1}\right)}
\end{aligned}
$$

iii) Figure 3 shows the ranking of $k_{1}, k_{2}, k_{3}$ and $k_{4}$.

$$
\begin{aligned}
& { }^{19} \text { With } \pi^{L}=\frac{1}{\omega}\left(\int_{0}^{\frac{p_{2}^{L}-p_{1}^{L}-\left(r_{2}^{L}-r_{1}^{L}\right)}{q_{2}-q_{1}}}\left(p_{2}^{L}-r_{2}^{L}-\omega q_{2}\right) d \omega+\int_{\frac{p_{2}^{L}-p_{1}^{L}-\left(r_{2}^{L}-r_{1}^{L}\right)}{q_{2}-q_{1}}}^{\frac{p_{1}^{L}-r_{1}^{L}}{q_{1}}}\left(p_{1}^{L}-r_{1}^{L}-\omega q_{1}\right) d \omega\right), \\
& \text { and } \pi^{U}=\frac{1}{\omega}\left(\int_{0}^{\frac{r_{1}^{U}-r_{2}^{U}}{q_{2}-q_{1}}}\left(p^{U}-r_{2}^{U}-\omega q_{2}\right) d \omega+\int_{\frac{r_{1}^{U}-r_{2}^{U}}{q_{2}-q_{1}}}^{\frac{p^{U}-r_{1}^{U}}{q_{1}}}\left(p^{U}-r_{1}^{U}-\omega q_{1}\right) d \omega\right) \\
& { }^{20} \text { With } S C^{L}=\frac{1}{\bar{\theta}}\left(\int_{\frac{p}{1}}^{\frac{p_{2}^{L}-p_{1}^{L}}{q_{2}-q_{1}}}\left(\theta q_{1}-p_{1}^{L}\right) d \theta+\int_{\frac{p_{2}^{L}-p_{1}^{L}}{q_{2}}}^{\bar{\theta}}\left(\theta q_{2}-p_{2}^{L}\right) d \theta\right), \\
& \text { and } S C^{U}=\frac{1}{\bar{\theta}} \int_{\frac{p^{U}}{q_{1}}}^{\bar{\theta}}\left(\theta q_{1}-p^{U}\right) d \theta .
\end{aligned}
$$




\section{Figures}

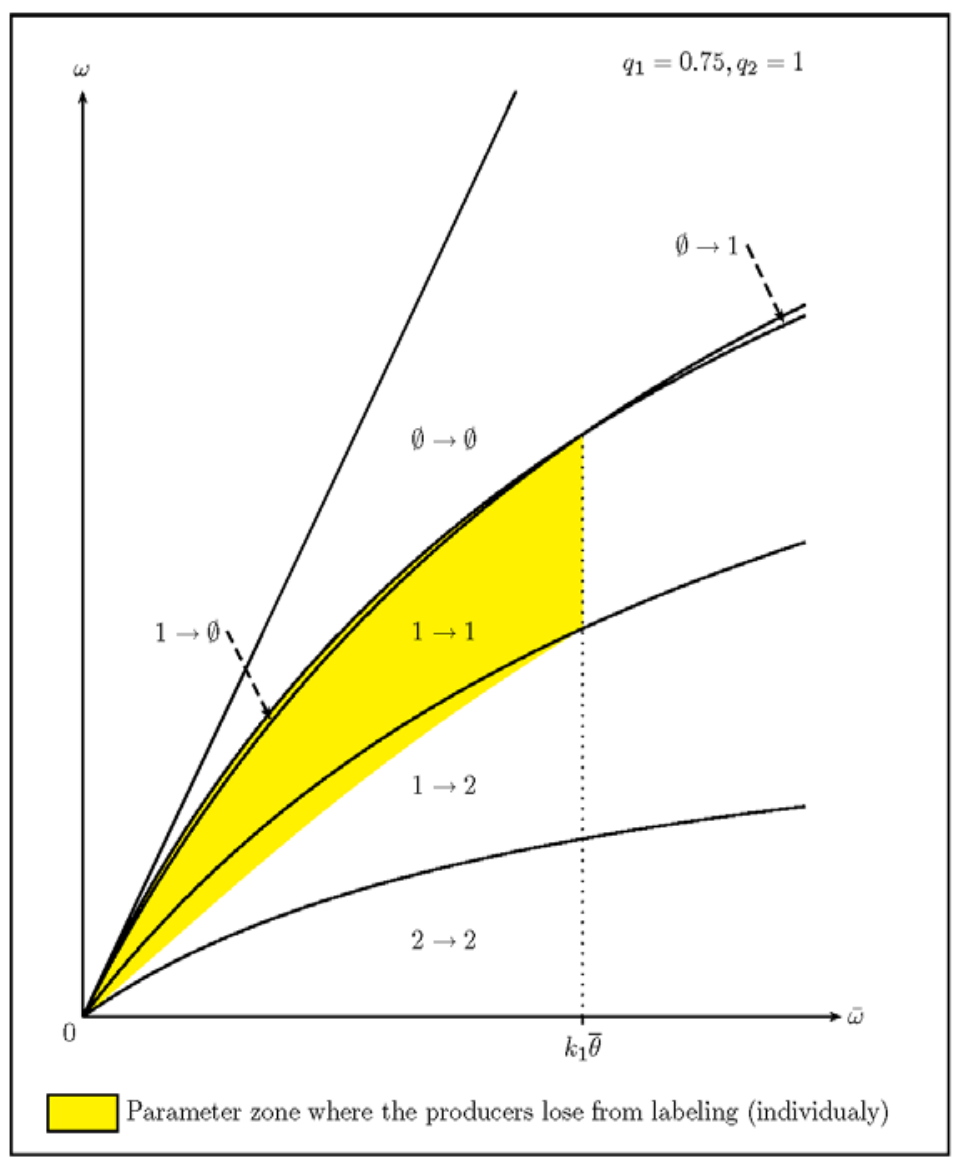

Producers' choice are represented by $x \rightarrow y, x$ being the choice without labeling, $y$ being the choice whith labeling. $\emptyset$ corresponds to an inactive producer.

Figure 1. Producers' choice according to $\omega$. 


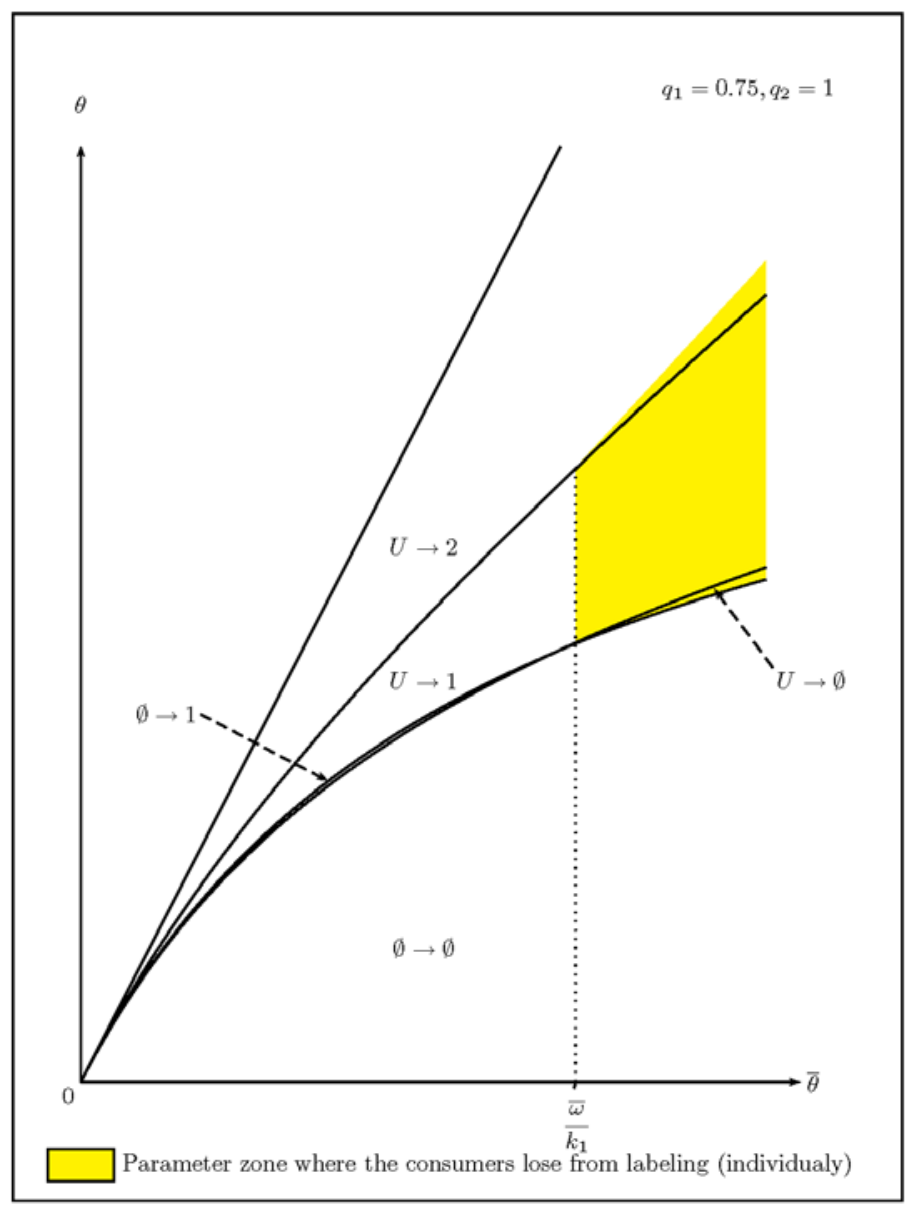

Consumers' choice are represented by $x \rightarrow y, x$ being the choice without labeling. $y$ being the choice whith labeling. $U$ corresponds to the unlabeled product. 0 corresponds to an inactive consumer.

Figure 2. Consumers' choice according to $\theta$. 


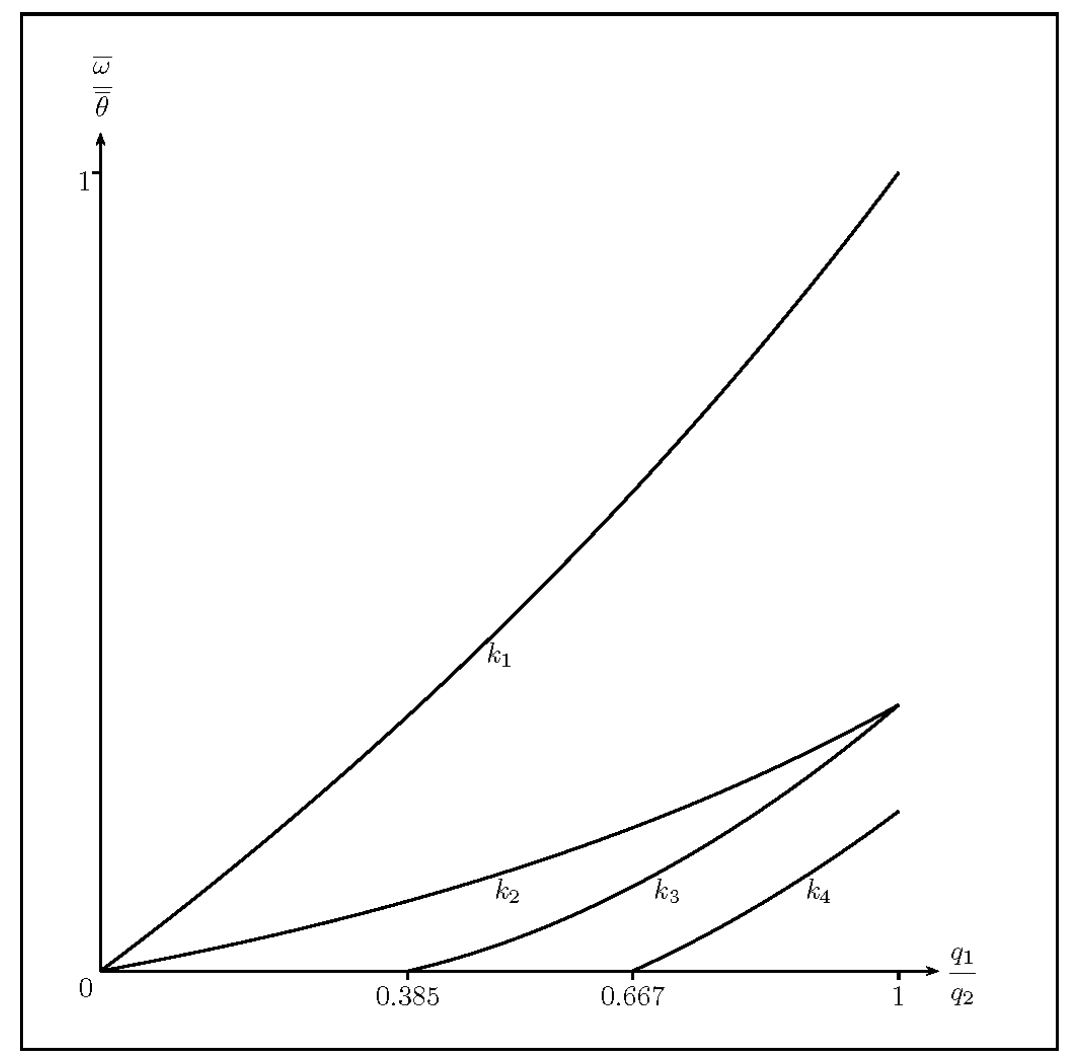

Figure 3. Ranking of $k_{1}, k_{2}, k_{3}$ and $k_{4}$. 